\title{
Study of the Adsorption Kinetics of Iron Ion from Wastewater using Banana Peel
}

\author{
Suman Lal Shrestha \\ Department of Chemistry, Patan Multiple Campus, Tribhuvan University, Lalitpur, Nepal
}

*Corresponding Author: Suman Lal Shrestha, Department of Chemistry, Patan Multiple Campus, Tribhuvan University, Lalitpur, Nepal

\begin{abstract}
The adsorption capacity of the chemically modified bio-sorbent of charred banana peel (CBP) with $1: 2(w / v)$ concentrated sulfuric acid was studied to remove the Fe (II) ions from industrial wastewater and the applicability of Langmuir and Freundlich isotherms was tested. The adsorption kinetics of the Fe (II) ions onto the CBP was studied using pseudo-first order, pseudo-second order and second order kinetics equations. Result shows that the optimum $\mathrm{pH}$ for Fe (II) adsorption onto the CBP was found to be 3 and the adsorption efficiency was found to be about $98 \%$ and the maximum adsorption capacity was found to be $33.79 \mathrm{mg} / \mathrm{g}$. These results showed that the CBP may be an attractive alternative for treatment of the industrial wastewater contaminated with $\mathrm{Fe}$ (II) ions.
\end{abstract}

Keywords: Charred banana peel, Adsorption isotherm, Fe (II), Batch kinetics, pH.

\section{INTRODUCTION}

There is a growing concern for the effective treatment of wastewater contaminated with heavy metal. Most of the heavy metals are highly toxic even in trace concentration [1]. Most of the common methods used to remove heavy metals from wastewater are chemical reduction followed by precipitation, membrane filtration, ion-exchange and adsorption onto activated carbon. Among these, adsorption by activated carbon has been used as an effective method to remove these heavy metals in trace concentration. However, the activated carbon is expensive and requires chelating agents to enhance its performance, thereby increasing treatment cost. For this reason, it is desirable to develop low cost and efficient adsorbent for removal of heavy metals from wastewater. Recently, adsorptions of metals by using bio-adsorbents are in progress $[2,3]$. Different types of industrial and agricultural bio-wastes are investigated as bio-adsorbent such as sugarcane bagasse [4], rice husk [5], olive stone [6], clay minerals [7-9], used tea leaves [10], wheat straw [11], chitin and chitosan [12]. They are easily available, economically acceptable and chemically less polluting substances often with high affinity and binding capacity of metals. In adsorption process, metal ions from solution are transported to the surface of the adsorbent and then attached due to the physical and chemical interaction between the metal ions and the functional groups on the surface of the adsorbent [13-19].

Iron is one of the major constituents of the lithosphere and comprises approximately $5 \%$ of it [20]. It is a dietary requirement for most organisms and plays an important role in many processes and is routinely detected in drinking water as well as municipal waste effluent, particularly where iron and steels are manufactured. In human, the minimum daily requirement for iron depends on age, sex, physiological status and iron bioavailability. It was reported that the uptake of iron ranges from about 10 to $50 \mathrm{mg} /$ day [21]. In the drinking water, iron concentration about $2 \mathrm{ppm}$ or less amount does not pose for a health hazard and the concentrations of 1-3 ppm of iron can be assumed to be acceptable level for drinking water [22]. It was reported that the excessive accumulation of iron in human body causes a disorder disease of hemato-chromatosis [22]. Since the human body has limited ways of eliminating the overdose iron, it accumulates in human body organs like in liver, bone marrow, pancreases and testicles and hence these human organs cannot function properly. For example, iron deposit in the liver and in the pancreas cause liver cirrhosis and diabetes mellitus, respectively [22]. The US Environmental Protection Agency (US EPA) has been established a secondary drinking water regulation of $0.3 \mathrm{ppm}$ for iron in drinking water [21]. Exceeding iron concentration more than 0.3 ppm causes adverse effects on human beings. 
Pollution caused by the excess amounts of iron in the water is a great problem for its safe uses in Nepal. In this context, it is necessary to develop the more reliable adsorbent using different types of bio-adsorbents those are locally available in cheap. The main aims of this study are to prepare a low cost bio-adsorbent from the CBP, to increase the adsorption capacity of $\mathrm{Fe}$ (II) from wastewater, to study the effect of initial $\mathrm{pH}$, adsorbent dose, initial concentration of the bio-adsorbate and contact time, to study the kinetics of the removal of Fe (II) from wastewater and to investigate the maximum adsorption capacities of the modified CBP.

\section{MATERIALS AND MeTHODS}

\subsection{Preparation of CBP Bio-adsorbent}

The banana peel was collected from different fruit seller of Bharatpur municipality of Chitwan and the collected peel was cleaned by distilled water and was dried to make its powder. The grinded banana peel powdered was sieved using 300 micron mesh. About 300 grams of the powder banana peel was treated with $600 \mathrm{~mL}$ concentrated sulfuric acid for 24 hours and then washed until completely removed of acid using distilled water. The washed material is called CBP bio-adsorbent and it was dried and stored in air tight sample bottle.

\subsection{Determination of Fe (II) Ions in Wastewater}

The commonly used method for the spectro-photometric determination of iron (II) ions in sampled wastewater involved the complexation of $\mathrm{Fe}^{2+}$ with 1, 10-phenanthroline to produce an intensely orange-red complex of ferrous tris-1, 10-phenanthroline as discussed in detail elsewhere [23]. The required concentration of the working iron (II) solution which was collected directly from the disposure wastewater from Mangalpur Iron Industry was prepared by diluting the required volume of the sampled stock solution from the sampling site.

\subsection{Batch Adsorption Study}

The absorption of light by the orange-red complex of ferrous tris-1, 10-phenanthroline was measured against reagent blank at different wavelength ranging from $420-560 \mathrm{~nm}$ using the spectrophotometer and $510 \mathrm{~nm}$ was found to be the $\lambda_{\max }$ of the iron (II) complex. The $\mathrm{pH}$ of the ferrous tris-1, 10phenanthroline complex solution was adjusted from 1.5 to 4.5 by using $0.1 \mathrm{M} \mathrm{NaOH}$ and $0.1 \mathrm{M} \mathrm{HCl}$ solutions and the effect of the $\mathrm{pH}$ onto the adsorption was studied. For batch adsorption studies, 40 $\mathrm{mg}$ of CBP was mixed with $40 \mathrm{~mL}$ of corresponding orange-red complex of ferrous tris-1, 10phenanthroline solutions adjusting the initial $\mathrm{pH}$ at 3 and was equilibrated in a conical flask, as a maximum adsorption of the iron (II) complex was confirmed in these conditions. The vessel was shaken for 5 hours using a shaker at room temperature and was left for 24 hours to attain equilibrium. The equilibrium concentration of iron (II) complex solution was determined using UV-visible spectrophotometer at $510 \mathrm{~nm}$, after centrifuging the bio-adsorbent CBP-iron (II) complex mixture. The amount of Fe (II) ions adsorbed onto unit mass of the bio-adsorbent was calculated from the mass balance equation given by equation (1). The $\mathrm{C}_{t}=\mathrm{C}_{\mathrm{e}}$ and $\mathrm{Q}_{\mathrm{t}}=\mathrm{Q}_{\mathrm{e}}$ at equilibrium, then the mass balance equation takes the form of equation (2) given below.

$\mathrm{Q}_{\mathrm{t}}=\frac{\left(\mathrm{C}_{\mathrm{o}}-\mathrm{C}_{\mathrm{t}}\right) \times \mathrm{V}}{\mathrm{m}}$
$\mathrm{Q}_{\mathrm{e}}=\frac{\left(\mathrm{C}_{\mathrm{o}}-\mathrm{C}_{\mathrm{e}}\right) \times \mathrm{V}}{\mathrm{m}}$

where, $Q_{t}$ is the amount of $\mathrm{Fe}$ (II) uptake per unit mass of adsorbent $(\mathrm{mg} / \mathrm{g})$ at time ' $\mathrm{t}$ '. $\mathrm{C}_{\mathrm{o}}$ and $\mathrm{C}_{\mathrm{t}}$ are the iron (II) complex concentrations in liquid phase ( $\mathrm{mg} / \mathrm{L}$ ) initially and at time $\mathrm{t}$, respectively. $\mathrm{V}$ is the volume of the test solution of iron (II) in liter and $m$ is the mass of the dry adsorbent in gram.

The percentage removal of iron (II) (A \%) from the aqueous solution was calculated using following relation (3).

$\mathrm{A} \%=\frac{\mathrm{C}_{0}-\mathrm{C}_{\mathrm{t}}}{\mathrm{C}_{\mathrm{o}}} \times 100$

In order to evaluate the effect of contact time on the removal of Fe (II) from wastewater solution by the CBP bio-adsorbent, several experiments were performed using $2 \mathrm{mg} / \mathrm{L} \mathrm{Fe}$ (II) solution with $40 \mathrm{mg}$ 
of the CBP in $40 \mathrm{~mL}$ of $\mathrm{Fe}$ (II) solution at the optimum $\mathrm{pH}$ of 3 for different interval of time from 10 to 2880 minutes. Then the bio-adsorbent CBP-iron (II) complex suspension was decanted and was separated using centrifugal machine and was analyzed for equilibrium Fe (II) concentration. The data obtained were analyzed with pseudo-first order, pseudo-second order and second order kinetic models. Similarly, Langmuir (equations 4 and 5) and Freundlich (equations 6 and 7) adsorption equations were applied to evaluate the maximum Fe (II) ions removable capacity by the CBP bioadsorbent in this study.

$\mathrm{Q}_{\mathrm{e}}=\frac{\mathrm{Q}_{\max } \mathrm{bC}_{\mathrm{e}}}{\left(1+\mathrm{bC}_{\mathrm{e}}\right)}$

$\frac{\mathrm{C}_{\mathrm{e}}}{\mathrm{Q}_{\mathrm{e}}}=\frac{\mathrm{C}_{\mathrm{e}}}{\mathrm{Q}_{\max }}+\frac{1}{\mathrm{Q}_{\max } \cdot \mathrm{b}}$

$\mathrm{Q}_{\mathrm{e}}=\mathrm{K}_{\mathrm{F}} \mathrm{C}_{\mathrm{e}}^{1 / \mathrm{n}}$

$\log \mathrm{Q}_{\mathrm{e}}=\log \mathrm{K}_{\mathrm{F}}+1 / \mathrm{n} \log \mathrm{C}_{\mathrm{e}}$

Where, $\mathrm{Q}_{\mathrm{e}}(\mathrm{mg} / \mathrm{g})$ is the amount of adsorption of iron (II); $\mathrm{C}_{\mathrm{e}}(\mathrm{mg} / \mathrm{L})$ is the equilibrium concentration of iron (II) after adsorption, $\mathrm{Q}_{\max }(\mathrm{mg} / \mathrm{g})$ is the maximum adsorption capacity, $\mathrm{b}(\mathrm{L} / \mathrm{mg})$ is the adsorption energy, $\mathrm{K}_{\mathrm{F}}$ and $1 / \mathrm{n}$ are Freundlich constants related to the adsorption capacity and adsorption intensity, respectively.

\section{RESULTS AND DISCUSSION}

\subsection{Effect of Initial pH of Fe (II) Solution}

The $\mathrm{pH}$ of an aqueous solution plays an important role in the removal capacity. In order to evaluate the effect of initial $\mathrm{pH}$ on the removal of Fe (II) from wastewater solution by the CBP bio-adsorbent, several batch adsorption experiments were performed at different initial $\mathrm{pH}$ values ranging from 1.0 to 4.5 at room temperature $\left(25^{\circ} \mathrm{C}\right)$. Figure 1 shows the changes of the percentage removal of the $\mathrm{Fe}$ (II) by the CBP bio-adsorbent as a function of the initial $\mathrm{pH}$ of the $\mathrm{Fe}$ (II) solution at room temperature. It can be observed that the percentage removal of Fe (II) from wastewater solution increased with increasing the initial $\mathrm{pH}$ of $\mathrm{Fe}$ (II) solution until it becomes maximum at $\mathrm{pH}$ 3.0. Thus, the optimal $\mathrm{pH}$ for the removal of Fe (II) from wastewater solution by the CBP bio-adsorbent is considered to be 3.0 and this $\mathrm{pH}$ value was adjusted for further adsorption study in this work.

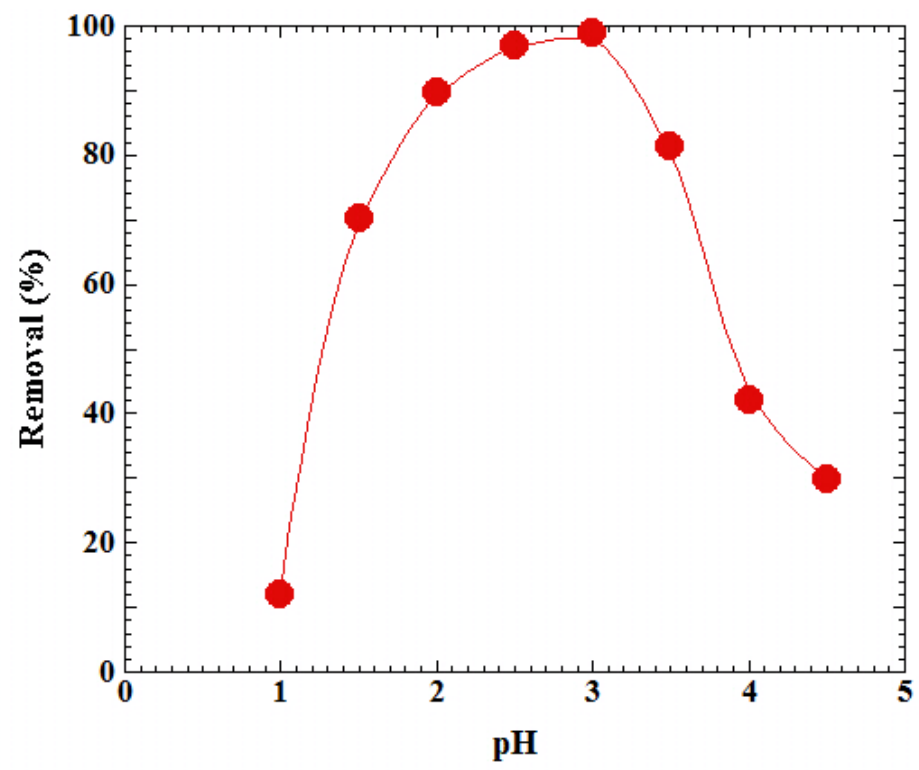

Figure1. Effect of the initial $\mathrm{pH}$ on removal of Fe (II) from industrial wastewater sample solution by the CBP bio-adsorbent

\subsection{Effect of Contact Time}

The effect of contact time was studied by taking $40 \mathrm{~mL}$ of the adsorbate solution containing $2 \mathrm{mg} / \mathrm{L}$ $\mathrm{Fe}$ (II) in a $100 \mathrm{~mL}$ Erlenmeyer flask with $40 \mathrm{mg}$ of the CBP bio-adsorbent at $\mathrm{pH}$ 3. The solution was 
stirred for different time intervals ranging from 10 to 2880 minutes. Figure 2 shows the removal efficiency of $\mathrm{Fe}$ (II) by the CBP is increased with contact time initially and it is remained constant after stirring for 240 minutes or more times. The iron (II) removal capacity by the used bio-adsorbent of CBP was found $98.05 \%$. Therefore, for the batch adsorption study of the Fe (II) from wastewater sample by CBP bio-adsorbent, the Fe (II)-CBP suspension was stirred for 5 hours in all adsorption studies and then the suspension was kept contact for about $24 \mathrm{~h}$ in the studies. From this experimental data, it was studied the adsorption kinetics which will be discussed subsequently in this paper.

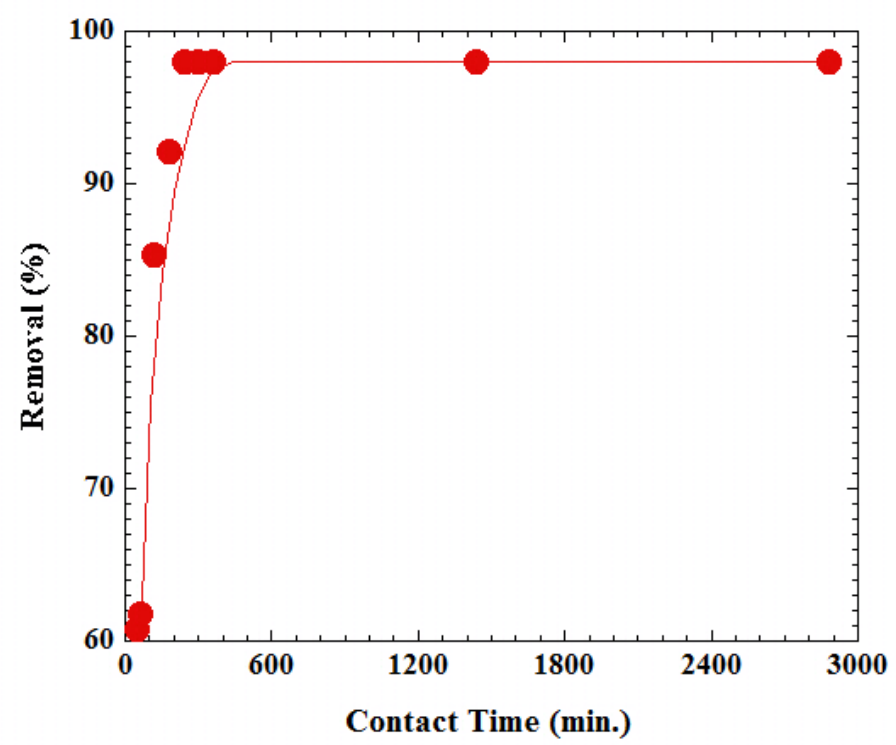

Figure2. Effect of contact time on removal of Fe (II) from industrial wastewater sample solution by the CBP bio-adsorbent

\subsection{Batch Adsorption Studies}

To study the removable of contaminated Fe (II) ions from wastewater sample by the bio-adsorbent CBP, Langmuir and Freundlich adsorption models were applied. Figure 3 shows the adsorption isotherm for the removable of the Fe (II) by the bio-adsorbent CBP sample at the given conditions as mentioned in experimental method above. The result revealed that the removable capacity of $\mathrm{Fe}$ (II) ions from wastewater sample solution by the bio-adsorbent CBP at room temperature of $25^{\circ} \mathrm{C}$. The result raveled that the maximum adsorption amounts of $\mathrm{Fe}$ (II) ions from wastewater is found to be about fifteen milligrams by one gram of the bio-adsorbent of CBP sample from this adsorption isotherm experiment.

The adsorption isotherm was evaluated using the linearized Langmuir and Freundlich isotherm equations (5) and (7), respectively, as mentioned above. The Langmuir constants (i.e., $\mathrm{Q}_{\max }$ and b) and Freundlich constants $\left(K_{F}\right.$ and $\left.n\right)$ were calculated from the linear plots of $C_{e} / Q_{e}$ versus $C_{e}$ as shown in Figs 4 and 5, respectively. The Langmuir and Freundlich constants and their linear coefficient of determination $\left(\mathrm{R}^{2}\right)$ were evaluated from the isotherm equations. The linear plots show that the removable of $\mathrm{Fe}$ (II) by the bio-adsorbent CBP obeys both the Langmuir and Freundlich adsorption isotherm equations. The high value of the linear coefficient of determination (i.e., $R^{2}=0.97828$ ) as shown in Fig. 5 confirmed that the Freundlich adsorption isotherm model is the best fitted than the Freundlich adsorption isotherm model. The linear correlation coefficient for Langmuir plot is found 0.94482 as shown Fig. 4.

The $\mathrm{Q}_{\max }$ (maximum adsorption capacity) value for the removable of $\mathrm{Fe}$ (II) from industrial wastewater by the bio-adsorbent CBP sample at room temperature in $\mathrm{pH} 3$ was estimated to be 33.79 $\mathrm{mg} / \mathrm{g}$ using Langmuir plot (Fig. 4). On the other hand, the energy of adsorption (i.e., b) for trapping the Fe (II) ions by the bio-adsorbent sample used in this study was calculated as $0.03 \mathrm{~L} / \mathrm{mg}$. The Freundlich constants $\mathrm{K}_{\mathrm{F}}$ and $1 / \mathrm{n}$ are related to the adsorption capacity and adsorption intensity, respectively. In the present study, the value of $1 / \mathrm{n}$ was found to be less than 1 which suggests the favorable adsorption behavior of Fe (II) ions onto the CBP bio-adsorbent. The KF value was calculated as $1.29 \mathrm{mg} / \mathrm{g}$ from Freundlich plot (Fig. 5). 


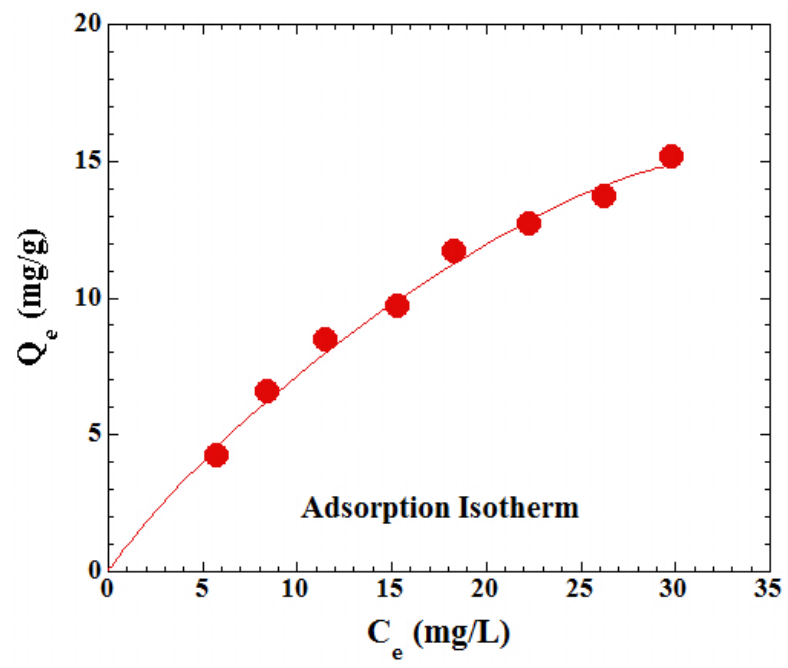

Figure3. Adsorption isotherm for the removal of $\mathrm{Fe}$ (II) from industrial wastewater sample by the CBP bioadsorbent at room temperature

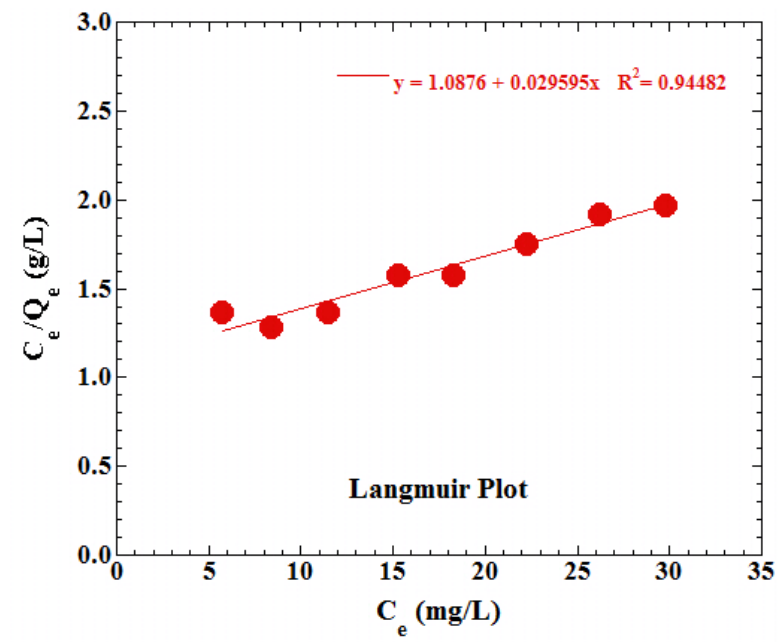

Figure4. Langmuir plot for the removal of Fe (II) from industrial wastewater sample by the CBP bio-adsorbent at room temperature

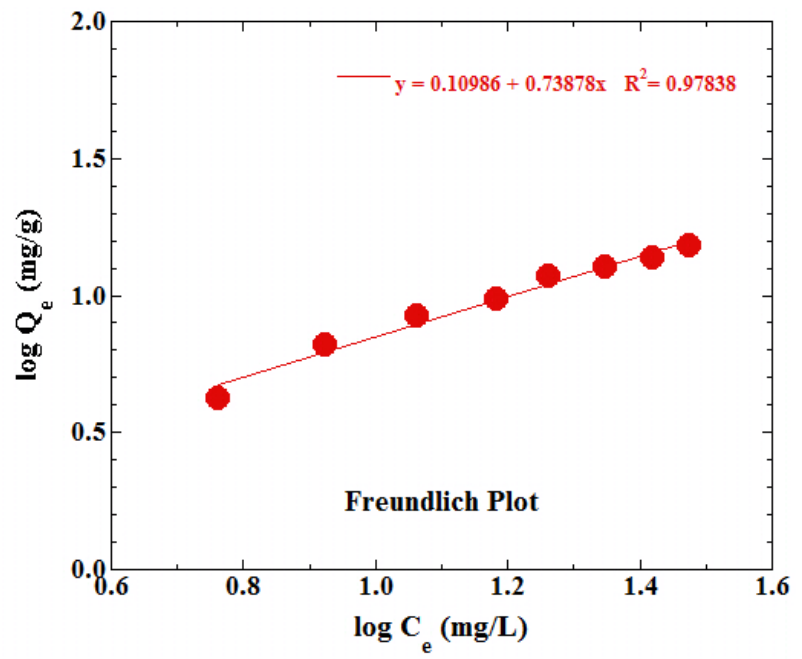

Figure5. Freundlich plot for the removal of $\mathrm{Fe}$ (II) from industrial wastewater sample by the CBP bioadsorbent at room temperature

\subsection{Adsorption Kinetics}

To study the kinetics of the adsorption process, pseudo-first, pseudo-second order and second order kinetic models have been used in this study. The pseudo-first order kinetic model was proposed by Lagergren and rate constant is determined by equation (8) as given below. 
$\log \left(\mathrm{Q}_{\mathrm{e}}-\mathrm{Q}_{\mathrm{t}}\right)=\log \mathrm{Q}_{\mathrm{e}}-\frac{\mathrm{K}_{1}}{2.303} \mathrm{t}$

Where, $\mathrm{Q}_{\mathrm{e}}(\mathrm{mg} / \mathrm{g})$ and $\mathrm{Q}_{\mathrm{t}}(\mathrm{mg} / \mathrm{g})$ are the amount of adsorbed metal ions at equilibrium and at any time $\mathrm{t}$ (min.), respectively and $\mathrm{K}_{1}$ is the rate constant of pseudo first order adsorption $\left(\mathrm{min}^{-1}\right)$. The adsorption rate constant, $\mathrm{K}_{1}$ and equilibrium adsorption capacity were calculated from the slope and intercepts of plot of $\log \left(\mathrm{Q}_{\mathrm{e}}-\mathrm{Q}_{\mathrm{t}}\right)$ versus $\mathrm{t}$, along with linear coefficient of determination (i.e., $\mathrm{R}^{2}=$ 0.9962) as shown in Fig. 6. Similarly, the kinetic study of Fe (II) ions adsorption onto the CBP bioadsorbent was analyzed using pseudo-second order kinetics model given by Ho and McKay [24]. It can be represented in its integrated form as shown in equation (9) as given below.

$\frac{\mathrm{t}}{\mathrm{Q}_{\mathrm{t}}}=\frac{1}{\mathrm{~K}_{2} \mathrm{Q}_{\mathrm{e}}^{2}}+\frac{\mathrm{t}}{\mathrm{Q}_{\mathrm{e}}}$

Where, $Q_{e}(\mathrm{mg} / \mathrm{g}), \mathrm{Q}_{\mathrm{t}}(\mathrm{mg} / \mathrm{g})$ and $\mathrm{t}\left(\mathrm{min}\right.$.) have the same meaning as mentioned in equation (8) and $\mathrm{K}_{2}$ $\left(\mathrm{g} / \mathrm{mg}^{-1} \cdot \mathrm{min}^{-1}\right)$ is the rate constant of pseudo second order adsorption.

The plot of $t / Q_{t}$ versus $t$, as shown in Fig. 7 gives $K_{2}$ and $Q_{e}$ values. The linear coefficient of determination (i.e., $\mathrm{R}^{2}=0.9998$ ) value is near unity, which shows that the pseudo second order model can be applied for the adsorption of Fe (II) onto the bio-adsorbent CBP and also confirmed the chemisorptions of metal ions [25]. It is meaningful to mention here that the second order kinetic model of adsorption cannot be applied for the removal of Fe (II) onto the bio-adsorbent CBP from the result shown in Fig. 8.

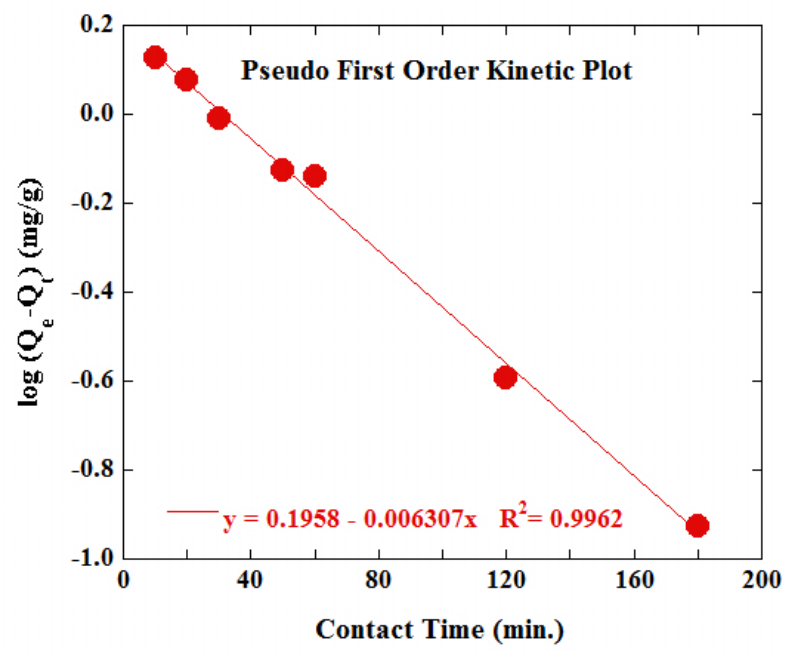

Figure6. Pseudo first order kinetic plot for the adsorption of $\mathrm{Fe}$ (II) from industrial wastewater sample onto the CBP bio-adsorbent at room temperature

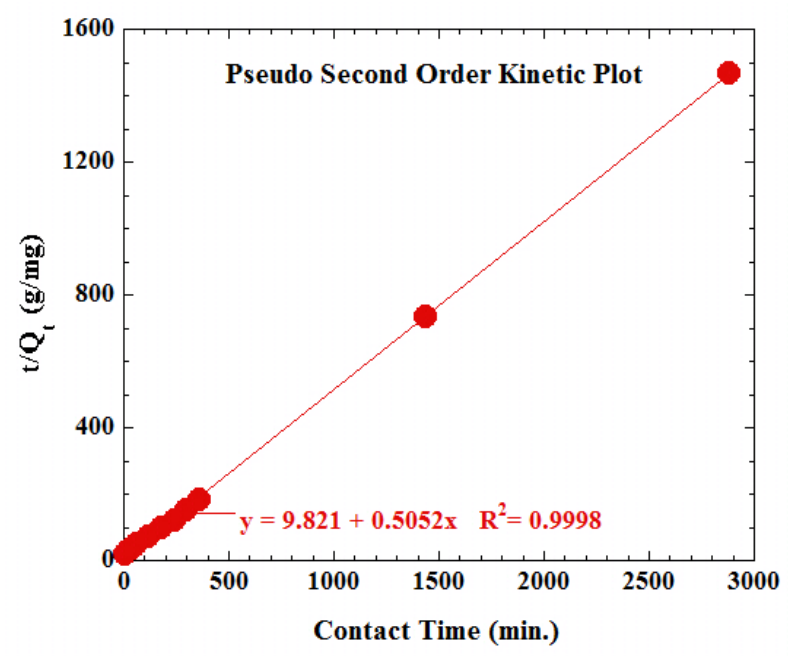

Figure7. Pseudo second order kinetic plot for the adsorption of Fe (II) from industrial wastewater sample onto the CBP bio-adsorbent at room temperature 


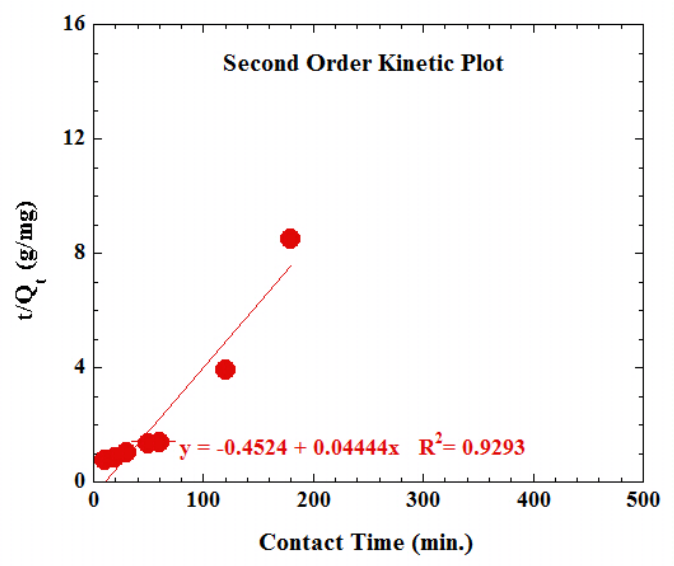

Figure8. Second order kinetic plot for the adsorption of Fe (II) from industrial wastewater sample onto the CBP bio-adsorbent at room temperature

\section{CONCLUSiOnS}

The batch adsorption experiments were performed at room temperature to study the removal of $\mathrm{Fe}$ (II) from wastewater solution by CBP bio-adsorbent. From the results and discussion of this study, the following conclusions are drawn:

1. It is found that the percent removal of Fe (II) from wastewater solution by the CBP bio-adsorbent sample is dependent on the $\mathrm{pH}$ and the maximum uptake of $\mathrm{Fe}$ (II) was found in $\mathrm{pH} 3.0$ at the initial concentration of $2 \mathrm{mg} / \mathrm{L}$.

2. Equilibrium uptake of Fe (II) was attained at about four hours or more period of time stirring.

3. The maximum adsorption capacity of the bio-adsorbent CBP sample for the removal of Fe (II) from wastewater solution was found to be $33.79 \mathrm{mg} / \mathrm{g}$ using adsorption isotherm equation.

4. The removal of Fe (II) by the modified clay samples obeys both Langmuir and Freundlich isotherm models. However, the Freundlich isotherm model is the best fitted than the Langmuir isotherm model.

5. The removal of $\mathrm{Fe}$ (II) from the sample by the used bio-adsorbent follows the pseudo-first order and pseudo-second order rate kinetics, although the pseudo-second order rate kinetic model was found to be best fitted.

6. The CBP bio-adsorbent can be used as good adsorbent for long time to remove the heavy metals from wastewater or drinking water.

\section{ACKNOWLEDGEMENTS}

Author would like to acknowledge to Mr. Manoj Bista and Ms. Bhagawati Mishra of the Department of Chemistry, Birendra Multiple Campus, Tribhuvan University, Bharatpur for thier help to complete this work.

\section{REFERENCES}

[1] Nurchi, V. M. and Villaescusa, I., Agricultural biomasses as sorbents of some trace metals, Coordination Chemistry Review, 252(10/11), pp 1178-1188 (2008). doi:10.1016/j.ccr.2007.09.023

[2] Volesky, B. and Holan, Z. R., Biosorption of heavy metals, Biotechnology Progress, 11(3), pp 235-250 (1995). doi:10.1021/bp00033a001

[3] Das, N., Vimala, R. and Karthika, P., Biosorption of heavy metals - an overview, Indian Journal of Biotechnology, 7, pp 159-169 (2008).

[4] Homagai, P. L., Ghimire, K. N. and Inoue, K., Preparation and characterization of charred xanthated sugarcane bagasse for the separation of heavy metals from aqueous solutions, Separation Science and Technology, 46(2), pp 330-339 (2011). doi:10.1080/01496395.2010.506903

[5] Kumar, U. and Bandyopadhyay, M., Sorption of Cadmium from aqueous solution using pretreted rice husk, Bioresource Technology, 97(1), pp 104-109 (2006). doi:10.1016/j.biortech.2005.02.027

[6] Blazquez, G., Hernainz, F., Calero, M. and Ruiz-Nu-nez, L. F., Removal of cadmium ions with olive stone: the effect of some parameters, Process Biochemistry, 40(8), pp 2649-2654 (2005). doi:10.1016/ j.procbio.2004.11.007

[7] Duwal, N., Joshi, S. and Bhattarai, J., Study on the removable of methylene blue by calcined-Kamerotar clays as an eco-friendly low cost adsorbent, International Journal of Advanced Research and Chemical Sciences, 3(11), pp 1-8 (2016). doi:10.20431/2349-0403.0311001 
[8] Duwal, N., Investigation on the selective adsorption of methylene blue onto clay minerals of Kamerotar of Bhaktapur (Nepal), in M. Sc. dissertation, Central Department of Chemistry, Tribhuvan University, Kirtipur, Kathmandu, Nepal, pp 50 (2013). doi:10.13140/RG.2.2.18048.02562

[9] Bhattarai, J., Adsorption of indigo-carmine dye on kaolin in aqueous medium, Tribhuvan University Journal, 17(1), pp 10-19 (1994).

[10] Islam, T. A., Begum, H. A., Hossain, M. A. and Rahman, M. T., Removal of Pb(II) from aqueous solution by sorption on used tealeaves, Journal of Bangladesh Academy of Sciences, 33( 2), pp 167-178 (2009). doi: 10.3329/jbas.v33i2.4100

[11] Chen, S., Yue, Q., Gao, B. and Xu, X., Equilibrium and kinetic adsorption study of the adsorptive removal of Cr (VI) using modified wheat residue, Journal of Colloid and Interface Science, 349(1), pp 256-264 (2010). doi:10.1016/j.jcis.2010.05.057

[12] Vijayarhavan, K., Palanivelu, K. and Veian, M., Biosorption of copper (II) and cobalt (II) from aqueous solutions by crab shell particles, Bioresource Technology, 97(12), pp 1411-1419 (2006). doi:10.1016/j.biortech.2005.07.001

[13] Sun, G. and Shi, W., Sunflower stalks as adsorbents for the removal of metal ions from wastewater, Industrial and Engineering Chemistry Research, 37(4), pp 1324-1328 (1998). doi:10.1021/ie970468j

[14] Deng, S., Bai, R. and Chen, J. P., Aminated polyacrylonitrile fibers for lead and copper removal, Langmuir, 19(12), pp 5058-5064 (2003). doi:10.1021/la034061x

[15] Deng, S., Bai, R. and Chen, J. P., Behaviors and mechanisms of copper adsorption on hydrolysed polyacrylonitrile fibers, Journal of Colloid and Interface Science, 260(2), pp 265-272(2003). doi:10.1016/S0021-9797(02)00243-6

[16] Mahvi, A. H., Naghipour, D. and Vaezi, F., Tea waste as an adsorbent for heavy netal removal from industrial wastewaters, American Journal of Applied Sciences, 2(1), pp 372-375 (2005). doi:10.3844/ajassp.2005.372.375

[17] WanNgah, W. S. and Hanafiah, M. A. K. M., Removal of heavy metal ions from wastewater by chemically modified plant wastes as adsorbents: a review, Bioresource Technology, 99(10), pp 3935-3948 (2008). doi:10.1016/j.biortech.2007.06.011

[18] Basso, M. C., Cerrella, E. G. and Cukierman, A. L., Lignocellulosic materials as potential biosorbents of trace toxic metals from wastewater, Industrial and Engineering Chemistry Research, 41(15), pp 3580-3587 (2002). doi:10.1021/ie020023h

[19] Chen, S., Yue, Q., Gao, B. and Xu, X., Equilibrium and kinetic adsorption study of the adsorptive removal of Cr (VI) using modified wheat residue, Journal of Colloid and Interface Science, 349(1), pp 256-264 (2010). doi:10.1016/j.jcis.2010.05.057

[20] G. Karthikeyan, N. M. Andal and K. Anbalagan, Adsorption studies of iron (III) on chitin, Journal of Chemical Society, 117(6), pp. 663-672 (2005). doi:10.1007/BF02708296

[21] World Health Organization, Guidelines for drinking water quality, in Health criteria and other supporting information, $2^{\text {nd }}$ edition, Vol. 2, Geneva (1996).

[22] Lauffer, R., Iron and human diseases, CRC Press, London (1992).

[23] Adhikari, N. M., Study on the selective adsorption of Fe (II) from aqueous solution onto modified clays of Kamerotar area of Bhaktapur (Nepal), in M. Sc. dissertation, Central Department of Chemistry, Tribhuvan University, Kirtipur, Kathmandu, pp 54 + vii (2013).

[24] Ho, Y. S. and McKay, G., Pseudo second order model for sorption processes, Process Biochemistry, 34(5), pp 451-465 (1999). doi:10.1016/S0032-9592(98)00112-5

[25] Wankasi, D., Horsfall, J. M. and Spiff, A. I., Sorption kinetics of $\mathrm{Pb}^{2+}$ and $\mathrm{Cu}^{2+}$ ions from aqueous solution by Nipah palm (Nypa fruticans Wurmb) shoot biomass, Electronic Journal of Biotechnology, 9(5), pp 587592 (2006). doi:10.2225/vol9-issue5-fulltext-5

Citation: S. Shrestha, "Study of the Adsorption Kinetics of Iron Ion from Wastewater using Banana Peel", International Journal of Advanced Research in Chemical Science (IJARCS), vol. 5, no. 3, pp. 1-8, 2018. http://dx.doi.org/10.20431/2349-0403.0503001

Copyright: (c) 2018 Authors. This is an open-access article distributed under the terms of the Creative Commons Attribution License, which permits unrestricted use, distribution, and reproduction in any medium, provided the original author and source are credited. 